\title{
Prehospital monitoring in resuscitation : today and the future
}

\author{
ŠTEFEK GRMEC - GREGOR PROSEN • BARBARA KIT • \\ MATEJ STRNAD • PETRA KLEMEN
}

ŠTEFEK GRMEC $(\bowtie) \bullet$ GREGOR PROSEN • BARBARA KIT • MATEJ STRNAD • PETRA KLEMEN

Emergency Medical Center Maribor Medical Faculty, University of Maribor Medical Faculty, University of Ljubljana Ulica talcev 9. Maribor 2000, Slovenia Phone:+ 386423211234 E-mail:grmec-mis@siol.net

\begin{abstract}
There is growing evidence that early detection and response to physiological deterioration can improve outcome for patients. Working out-of-hospital, we often find ourselves in diagnostic dilemmas, thus more reliable data could change our actions as well as give better assessment of patient's condition. Therefore, we are always exploring new perspectives that could be transferred from experimental laboratory settings to our primary working area in the field to help us improve decision-making leading to better outcome. In the following sections, we represent our previous studies about the utility of continuous capnometry and the importance of point-of-care ultrasound in cardiopulmonary resuscitation (CPR), and discuss about the possible future use of transthoracic and transesophageal ultrasound, point-of-care biochemical monitoring, tissue oxygen saturation, pupillometry, and mixed and central venous oxygen saturation monitoring in the prehospital setting.
\end{abstract}

Keywords: cardiopulmonary resuscitation, pre-hospital monitoring, capnometry, point-of care ultrasound and biochemical monitoring, pupillometry, mixed and central venous oxygen saturation, review

\section{Introduction}

Emergency medicine in the highly advanced world is traditionally performed in two different ways. The first is the well known Anglo-American model (AAM) with skilled emergency departments (ED) and prehospital emergency medical service utilizing paramedics. The second is the so-called Franco-German model (FGM), which represents a system of specially trained prehospital emergency physicians beginning to treat patients at the scene and during transport to the hospital. $(1,2)$ The recent studies have shown that involvement of prehospital emergency physicians results in more frequent return of spontaneus circulation (ROSC) and reduced patient mortality. (3-5) Differences in survival and outcome have been reported between the two models when patients require cardiopulmonary resuscitation (CPR) advanced airway management or other invasive procedures, as well as advanced pharmacotherapy or fast diagnostic-based decisions. (6)

In Slovenia the physician-based model with prehospital units (PHUs) has been established. PHUs are full time emergency medical teams manned by an emergency physician, register nurse and medical technician/driver. Large $\mathrm{PHU}$ are located in hospitals. With this model we integrated prehospital and hospital emergency medicine and established circular model for emergency physicians (circulation among hospital and field). This model of effective interdisciplinary medical cooperation is essential for transfer of skills, care and monitoring from hospital to the field.

\section{Prehospital monitoring of critically ill patients}

The concept of critical care and CPR, "from flying blind to flying right« (7) and »thinking global - treating personal«, (8-10) requires guidelines established by objective and real-time measurements of patient's status and effectiveness with the option of adjusting interventions to attain a better outcome. This philosophy of approach generates personalized treatment and secondary prevention of complications.

There is growing evidence that early detection and response to physiological deterioration can improve outcome for patients. Options for real-time physiological assessment and optimal haemodynamic monitoring during resuscitation in the field are limited by logistical difficulties, costs and training. The level of monitoring of patients in prehospital setting must increase significantly in the future and many more patients must be monitored continuously rather that intermittently. (11)

Working out-of-hospital, we often find ourselves in diagnostic dilemmas, thus more reliable data could change our actions as well as give better assessment of patient's condition. Therefore, 
Table 1. Current applications of capnography.

\begin{tabular}{ll}
\hline Clinical use & Clinical application \\
\hline $\begin{array}{l}\text { Endotracheal intubation } \\
\begin{array}{l}\text { Detection of mechanical } \\
\text { ventilation disconnection }\end{array}\end{array}$ & $\begin{array}{l}\text { Verification of endotracheal tube placement } \\
\text { tubes will quickly alert the clinician of tube displacement if the capnogram } \\
\text { is lost }\end{array}$ \\
\hline $\begin{array}{l}\text { Nasogastric tube placement } \\
\text { During insertion, capnography can be measured to prevent tracheal } \\
\text { placement of a nasogastric tube }\end{array}$ \\
\hline $\begin{array}{l}\text { PetCO } 2 \text { measurements that do not increase in response to CPR repre- } \\
\text { sent a low chance of patient survival }\end{array}$ \\
$\begin{array}{l}\text { Asse of capnometry/capnography throughout a resuscitative effort will } \\
\text { provide information regarding the patient's ROSC and response to } \\
\text { resuscitation }\end{array}$ \\
\hline $\begin{array}{l}\text { Detection of alveolar } \\
\text { dead space changes }\end{array}$ \\
$\begin{array}{l}\text { Identification of alveolar } \\
\text { emptying patterns }\end{array}$
\end{tabular}

CPR, cardiopulmonary resuscitation; $\mathrm{PetCO}_{2}$, Partial pressure of end-tidal carbon dioxide; ROSC, return of spontaneous circulation.

we are always exploring new perspectives that could be transferred from experimental laboratory settings to our primary working area in the field to help us improve decision-making leading to better outcome.

In the following sections, we represent our previous studies about the utility of continuous capnometry and the importance of point-of-care ultrasound in CPR, and discuss about the possible future use of transthoracic and transesophageal ultrasound, point-of-care biochemical monitoring, tissue oxygen saturation, pupillometry, and mixed and central venous oxygen saturation monitoring in the prehospital setting.

\section{Partial pressure of end-tidal carbon dioxide (PetCO2)}

The $\mathrm{PetCO}_{2}$ provides an estimate of the alveolar $\mathrm{CO}_{2}$ tension and reflects the combined effects of $\mathrm{CO}_{2}$ production, $\mathrm{CO}_{2}$ transport (to the lungs), and $\mathrm{CO}_{2}$ elimination modulated by the ana- tomical and physiological dead space. $(12,13)$ The current applications of capnography are shown in table 1.

\section{Capnography/capnometry and verification of endotra- cheal tube placement}

In one of our first studies, Grmec (14) observed all adult patients who were intubated by emergency physicians in the field. The position of an endotracheal tube was initially evaluated by auscultation. Capnometry and capnography were then performed with infrared method. The physicians searched for the characteristic $\mathrm{CO}_{2}$ waveform and at the same time they determined the values of PetCO 2 . Over a four year period, 345 patients requiring emergency intubation were included. Indications for intubation included cardiac arrest $(n=246$, $71 \%$ ) and non-arrest conditions ( $n=99$; $29 \%$ ). In this study capnography had a $100 \%$ sensitivity and specificity in both arrest and non-arrest patients, com- pared to capnometry which had $88 \%$ sensitivity and $100 \%$ specificity in the arrest population. This study showed that if capnographic waveform during cardiac arrest and resuscitation was present, regardless of its amplitude, the endotracheal tube could be confidently judged to be correctly placed.

In another study, Grmec and Mally (9) compared three different methods for immediate confirmation of endotracheal tube placement in patients with severe head injury. 81 patients were enrolled in this study. The initial capnometry (sensitivity 100\%, specificity 100\%), capnometry after sixth breath (sensitivity $100 \%$, specificity $100 \%$ ), and capnography after sixth breath (sensitivity $100 \%$, specificity 100\%) were significantly better indicators for tracheal tube placement than auscultation (sensitivity $94 \%$, specificity $66 \%, p<0.01$ ). In this study we concluded that auscultation alone was not a reliable method to confirm endotracheal tube placement 
in patients with severe head injury in the prehospital setting. Both studies $(14,9)$ confirmed that the capnography is the most reliable technique for identifying correct tube placement in arrest and non-arrest intubations. For tracheal tube confirmation and prevention of dislodgement, the verification methods should include the combination of clinical signs and the use of adjunctive devices such as the presence of exhaled $\mathrm{CO}_{2}$ and oesophageal detection devices. Once a correct placement has been confirmed, the endotracheal tube should be secured. Confirmation of a tube placement is a dynamic process, requiring ongoing patient assessment. (15)

\section{Capnography in cardiac arrest and cardiopulmonary resuscitation}

During CPR, the PetCO 2 correlates with cardiac output and, consequently, it has a prognostic value. Grmec and Klemen (16) analysed the utility of $\mathrm{PetCO}_{2}$ as a prognostic indicator of initial outcome of resuscitation in adult victims of out-of-hospital non-traumatic cardiac arrest. 139 adult patients were prospectively analysed. The initial, final, average, minimal and maximal $\mathrm{PetCO}_{2}$ were significantly higher in resuscitated patients than in non-resuscitated patients. Using an initial, average and final $\mathrm{PetCO}_{2}$ value of $10 \mathrm{mmHg}$, we correctly identified $100 \%$ of the patients who were subsequently resuscitated with an acceptable specificity $(74.1 \%$; 90\%; 81.4\%). Important observation from this study was that none of the patients with an average, initial and final etCO $\mathrm{C}_{2}$ level of less than $10 \mathrm{mmHg}$ were resuscitated. Data from this prospective clinical trial indicate that initial, average and final $\mathrm{PetCO}_{2}$ monitoring during CPR correlate with resuscitation efforts. $\mathrm{PetCO}_{2}$ monitoring has potential as a non-invasive indicator of cardiac output during resuscitation and a prognostic indicator for resuscitation.

A similar study was published by Grmec and Kupnik (17) where capnography was added to the Mainz Emergency Evaluation Scoring (MEES) system. 246 adult patients with nontraumatic normothermic cardiac arrest were studied. Initial and final (post-CPR) values of $\mathrm{PetCO}_{2}$ were significantly higher in the group of patients with ROSC and in those who survived than in the group of patients without ROSC and those who died. All the patients with ROSC and those who survived had initial values of $\mathrm{PetCO}_{2}$ higher than $10 \mathrm{mmHg}$. The mean of all final values of Pet $\mathrm{CO}_{2}$ in patients without ROSC was 15,9+/-5,1 $\mathrm{mmHg}$ and the mean of all final values in patients with ROSC was 32,3+/-4,1 $\mathrm{mmHg}$. Our study shows that the initial and final values of $\mathrm{PetCO}_{2}$ lower than $15,9 \mathrm{mmHg}$ correlate with higher mortality rate and values lower than 10 $\mathrm{mmHg}$ are incompatible with survival. This study confirmed that a new scoring system MEESc (MEES combined with capnometry), compared with MEES, is significantly better and has greater value in predicting survival after CPR in patients with normothermic nontraumatic cardiac arrest.

Grmec et al. (18) compared the initial $\mathrm{PetCO}_{2}$ and $\mathrm{PetCO}_{2}$ after 1 minute during CPR in two groups of patients: 1) cardiac arrest due to asphyxia with asystole or pulseless electrical activity (PEA) as the initial rhythm, and 2) primary cardiac arrest with ventricular fibrillation (VF) or pulseless ventricular tachycardia (VT) as the initial rhythm. The $\mathrm{PetCO}_{2}$ was measured immediately after intubation and then repeatedly every minute, both for patients with and without ROSC. We analyzed 44 patients with asphyxial cardiac arrest and 141 patients with primary cardiac arrest. The first group showed no significant difference in the initial value of $\mathrm{PetCO}_{2}$, even when we compared those with and without ROSC. There was a significant difference in $\mathrm{PetCO}_{2}$ after 1 minute of CPR between those patients with ROSC and those without ROSC. The mean value for all patients was significantly higher in the group with asphyxial arrest. In the group with VFNT arrest there was a significant difference in the initial $\mathrm{PetCO}_{2}$ between patients with and without ROSC. In all patients with $\mathrm{ROSC}$ the initial $\mathrm{PetCO}_{2}$ was higher than $10 \mathrm{mmHg}$. The initial PetCO $\mathrm{P}_{2}$ was significantly higher in asphyxial arrest than in VTNF cardiac arrest.

In another prospective study, Grmec et al. (19) analysed the outcome of patients with out-of-hospital cardiac arrest (OHCA) over a four year period using a modified Utstein style. We analysed the effects of various factors on outcome in $\mathrm{OHCA}$, especially $\mathrm{PetCO}_{2}$, efficacy of bystander CPR and their elementary knowledge of basic life support (BLS). We also examined motivation among potential bystanders and possible implementation for BLS education in our community. After treating OHCA by a physician-based prehospital medical team, ROSC was obtained in $61 \%$, the ROSC on admission was $50 \%$ and the overall survival to discharge was $21 \%$. Initial PetCO 2 , VF or pulseless VT as initial rhythm, bystander CPR, female sex, and arrival time were associated with improved ROSC when using multivariate analysis. Using the same method we found that bystander CPR, witnessed arrest, final $\mathrm{PetCO}_{2}$, initial $\mathrm{PetCO}_{2}$, and arrival time were associated with improved survival. A questionnaire filled by potential bystanders has revealed disappointing knowledge about BLS fundamentals. On the other side, there was a willingness of potential bystanders to take BLS training and to follow dispatchers' instructions by telephone on how to perform CPR.

Data from this and previous studies provide a strong support for $\mathrm{PetCO}_{2}$ value of $10 \mathrm{mmHg}$ to be a resuscitation threshold in the field. In our opinion, the initial value of $\mathrm{PetCO}_{2}$ should be included in every Utstein style analysis. In other studies $(20,21)$ we analyzed how changes in $\mathrm{PetCO}_{2}$ levels during CPR could predict the successful resuscitation, and serve as a tool for help in determining when to cease CPR efforts. $\mathrm{PetCO}_{2}$ values after 20 minutes of advanced life support (ALS) were $6.9+/-2.2 \mathrm{mmHg}$ in patients without ROSC and $32.8+/-9.1 \mathrm{mmHg}$ in patients with ROSC $(p<0.001)$. When a 20-minute $\mathrm{PetCO}_{2}$ value of $14.3 \mathrm{mmHg}$ was used as a screening test to predict ROSC, the sensitivity, specificity, 
positive predictive value, and negative predictive value were all $100 \%$.

\section{Point-of-care transthoracic ultrasound in prehospital CPR}

Point-of-care ultrasound differs from classic, comprehensive radiological examination in its focused search for life-threatening conditions and making direct clinical conclusions and pertinent decisions. Parallel to specific indications, there are systematic approaches and algorithms tailored to specific critical conditions, establishing ultrasound enhanced advanced life support ( cardiac arrest ultrasound exam, C.A.U.S.E).

In our prospective pilot study $(22,23)$ we evaluated the ability of focused echocardiography (FE) and capnography to differentiate between PEA (true cardiac standstill) and pseudoPEA (FE signs of spontaneous mechanical myocardial activity and valvular motion) in OHCA, and the potential survival benefits with modified treatment. In patients with a stable $\mathrm{PetCO}_{2}$ value during the compression pause and FE showing cardiac kinetic activity, the compression pause was prolonged for 15 seconds and additional 20 units of vasopressin were administered. If pulselessness persisted, the compressions were continued. Amongst the 16 patients in the study, 15 (94\%) achieved ROSC, with eight (50\%) attaining a good neurological outcome (Cerebral Performance Category 1 or 2). In a historic PEA group with stable $\mathrm{PetCO}_{2}$ values $(n=48)$, ROSC was achieved in $26(54 \%)$ and only four (8\%) attained Cerebral Performance Category 1 or 2. Echocardiographical verification of pseudo-PEA enabled additional vasopressor treatment and cessation of chest compressions and was associated with significantly higher rates of ROSC, survival to discharge and good neurological outcomes.

Use of ultrasound during CPR has helped immensely and opened a whole new plane of possible interventions mainly in search for reversible causes of cardiac arrest ("4H/4T"; i.e. hypoxia, hypovolemia, hypo/hyperkalemia/acidosis, tension pneumothorax, cardiac tamponade and pulmonary embolism). Several protocols of its possible use during CPR were developed, most notably Cardiac arrest ultra-sound exam -"CAUSE"(24) and Focused echocardiographic evaluation in resuscitation - FEER (25). These protocols have added an invaluable and previously impossible-to-assess reversible causes ("4H/4T") of OHCA. Both protocols are conceptually very similar, almost an extension to sonographic assesment of shock patient named "RUSH" (Rapid Ultrasound in SHock), (26) as PEA is mostly pathophysiologic continuation of decompensated shock.

Use of bedside cardiac echosonography has finally enabled diagnostic differentiation between PEA and pseudo-PEA. Pseudo-PEA can be viewed as ultimate stage of decompensated shock, before deterioration into asystole. In this regard, point-of-care ultrasound raises an important question; what defines cardiac arrest? With shockable rhythms and asystole the answer is quite obvious, but in PEA the definition can be more elusive and pulse check much less reliable.

Neurologists use transcranial Dopplerultrasound assesment of internal carotid flow (27) to pursue reperfusion. This method could also help emergency physicians, since cerebral perfusion is the main goal we want to achieve. But technique of transcranial Doppler-ultrasound is technically difficult to perfom and interpret and not always possible to perform in the first place. Recent article from Hass et al. (28) has made a great leap forward in introduction of extracranial-carotid artery Duplex sonography, assesing adequacy of flow where it ultimately matters - that flowing towards brain. This could finaly take us away from subjective assesment of adequacy of cerebral blood flow with finger pulse check towards objective measurement of carotid blood flow. Equally important, they have shown that their "extended FEEL" examination looking for reversible causes of cardiac arrest (through cardiac echosonography) and carotid artery Dupplex sonography are both feasible during busy and manytimes hectic resuscitation process.

\section{Emergency transesopha- geal echocardiography}

Emergency transesophageal echocardiography (TEE) is an important part of procedures during diagnosis and treatment of critically ill patients. TEE provides structural and physiological information in real time. (29) TEE reliably produces cardiac images and during CPR does not interfere with continuing resuscitation efforts unlike transthoracic echocardiography. (30) It provides much better view with continous monitoring of cardiac compressions and state of myocardial and valvuar activity, enhances the search for reversible causes of OHCA ("4H/4T") and enables diagnosis of valvular pathology and aortic dissection with higher sensitivity and specificity.

The purposes of TEE during CPR are: to determine the cause of sudden cardiac arrest (myocardial infarction, (31) pulmonary embolism, (32) cardiac tamponade, (33) endocarditis, (34) aortic dissection (35) and thus improves early goal directed therapy;

for hemodynamic monitoring (36) (detection of ROSC with TEE is more sensitive than palpation of peripheral pulse);

to identify clinical states that are incompatible with life.

One of the primary goals after successful resuscitation is assessment of cardiac function. TEE provides useful information about systolic function of the left ventricle (ejection fraction, systolic shortening fraction), diastolic left ventricular function (mitral flow profile, pulmonary venous flow profile), right ventricular function, regional wall motion abnormalities, preload (left ventricular end diastolic area index) and afterload (left ventricular wall tension) and as a result can modify early therapy leading to better resuscitation outcome. (36) Adequate education and training of emergency physicians and intensivists is crucial to further develop the use of transesophageal echocardiography 
in emergency department or intensive care unit setting.

\section{Tissue oxygen saturation and biochemical parameters}

Another promising new diagnostic modality that assesses adequacy of brain perfusion even closer is cerebral tissue oxygenation (commercial device INVOS $\left.{ }^{\circledR}\right)$. (37-39) Miniaturization of techonology has enabled the noninvasive, over-the-skin measurement of cerebral and peripheral tissue oxygenation and the adequacy of cerebral perfusion. Such data would give critical care physicians a valuable feedback into success of resuscitation - all that possibly real-time in the field.

In the past, management of circulatory state focused on macrocirculatory parameters such as arterial blood pressure, cardiac output and blood oxygen saturation. It is now becoming more and more apparent that it is not only macrocirculation that is important but mostly microcirculation. (40-42) Although easily measured, macrocirculatory parameters are rather poor surrogates of actual tissue perfusion and oxygenation. Blood lactate levels and base excess (BE) have been shown to correlate better with degree of tissue hypoxia. Nowadays they are becoming available at the point of care through recently introduced portable blood analyzers.

Alternative for monitoring adequacy of (cerebral) blood flow is laboratory measurement of biochemical parameters; both classical parameters of causes and effects of shock (cardiac troponin, D-dimer, plasma N-terminal proB-type natriuretic peptide (NT-proBNP), C-reactive protein, lactate, basic chemistry, blood count, arterial blood gas and acid-base status) as well as novel and more specific markers of cellular/ mitochondrial injury (eg. cytochrome). There are quite a few modern portable blood analysers (43-45) that can point us towards causes of OHCA (eg. cardiac troponins for acute myocardial infarction, D-dimer for pulmonary embolism), thus (in conjunction with point-of-care ultrasound) encompassing almost all reversible causes of OHCA- within minutes in the field.

Furthermore, there are numerous promising new markers of cellular injury being discovered, further enhancing our knowledge of relevant pathophysiologic processes and possible target interventions.

Tissue oxygen saturation is an important objective regarding microcirculation during CPR in the near future. In our future research we intend to measure tissue oxygen saturation $\left(\mathrm{StO}_{2}\right)$ during prehospital CPR in corelation with other well established parameters of effectiveness of CPR and predictors of outcome. We presume that $\mathrm{StO}_{2}$ real-time monitoring during CPR could serve as ultimate guide of adequacy of microcirculation.

After shock state, as well as in-post resuscitation period, $\mathrm{StO}_{2}$ decreases as a result of increased $\mathrm{O}_{2}$ demands to repay oxygen debt incurred during hypoperfusion. (46-50) In contrast, progresive cellular/mitochondrial damage during shock or cardiac arrest might increase $\mathrm{StO}_{2}$ as cellular uptake of oxygen is disabled.

Our idea is to draw corellation between $\mathrm{StO}_{2}$ and $\mathrm{PetCO}_{2}$ values to predict outcome of OHCA and to measure therapeutic efficacy during CPR and postresuscitation period.

\section{Pupilary monitoring during CPR}

Following promising experimential porcine model study (51) and clinical observational study, (52) pupilary size and pupilary light reactivity (PLR) might be important predictors of subcortical function and neurologic outcome as well as reliable indicators of cerebral perfusion during CPR. In our future study, we intend to measure pupilary size and PLR in concordance with other physiological parameters to assess hemodynamic effectiveness of CPR, to predict neurological outcome and to guide post-resuscitation treatment. $(53,54)$

We hypothesize that PLR at the start of CPR is inversely related with the time from collapse to initiation of CPR by professional rescuers as well as favorably influenced by bystander CPR. We also assume that PLR improves during $\mathrm{CPR}$ in relation to hemodynamic effectiveness of CPR and correlates with the subsequent recovery of neurological function in patients with ROSC.

\section{Mixed and central venous oxygen saturation}

Cardiac output can be monitored with different methods. Continuous monitoring of mixed venous $\left(\mathrm{SvO}_{2}\right)$ or central venous $\left(\mathrm{ScvO}_{2}\right)$ oxygen saturations have become widely used in clinical practice. (55) $\mathrm{ScvO}_{2}$ refers to hemoglobin saturation of blood in superior vena cava or in the right atrium. $\mathrm{SvO}_{2}$ refers to the same measurement in blood from the proximal pulmonary artery. The advantage of $\mathrm{ScvO}_{2}$ measurement is that it requires only the insertion of a central venous catheter rather than a pulmonary artery catheter (PAC). Venous saturation of blood can be measured continuously by insertion of invasive catheter that measures saturation of blood by spectrophotometry. (56)

In healthy individuals, values of $\mathrm{ScvO}_{2}$ are slightly lower than values of $\mathrm{SvO}_{2}$. However, in patients with heart failure, cardiogenic shock and particularly septic shock, values of $\mathrm{ScvO}_{2}$ become higher than values of $\mathrm{SvO}_{2}$. This is because of the redistribution of blood towards the cerebral and coronary circulation, away from the splenic, renal, and mesenteric vascular system, from where more deoxygenated venous blood flows into the inferior vena cava. (57) In critically ill patients, changes in $\mathrm{ScvO}_{2}$ paralleled changes in $\mathrm{SvO}_{2}$ and therefore the absolute differences between the two measurements are less important. $(58,59)$

The monitoring of $\mathrm{ScvO}_{2}$ reflects the balance between oxygen requirement and oxygen delivery, and therefore may be used to assess the adequacy of tissue oxygenation. (60) $\mathrm{ScvO}_{2}$ correlates with tissue oxygen extraction and rapidly changes with changes in cardiac output, hemoglobin concentra- 
tion, hemoglobin saturation and tissue oxygen utilization.

Oxidative balance in the critically ill is represented by $\mathrm{ScvO}_{2}$ level of $70 \%$. Uncompensated reduction of oxygen supply (due to lower cardiac output, reduction of hemoglobin concentration or saturation) or uncompensated increase in oxygen demand result in lower values of $\mathrm{ScvO}_{2}$. (61) $\mathrm{ScvO}_{2}$ values less than $65 \%$ are an early sign pointing towards development of shock. (61) The $\mathrm{ScvO}_{2}$ levels exceeding $75 \%$ can be found in sepsis, $(61,62)$ during anesthesia and in hypo- thermia or as physiological reserve (when all metabolic requirements are being met). Low $\mathrm{ScvO}_{2}$ values (less than $70 \%$ ) always indicate insufficient oxygen supply, $(61,63)$ while higher values (above $75 \%$ ) do not ensure normal tissue oxygenation (for example in sepsis). (61)

Monitoring of central venous saturation could provide useful information during CPR. Combined with measuring of $\mathrm{PetCO}_{2}(20)$ it can be used to improve the performance of chest compressions (depth, rate) during CPR and thus leading to better outcome. Sub- sequently, measuring of $\mathrm{ScvO}_{2}$ level in the early stage after successful resuscitation will guide us to appropriate therapy (volume resuscitation, inotropes, vasopressors). (11) Measuring of $\mathrm{ScvO}_{2}$ level can also be used in trauma patients to modify the therapy and improve survival. $(64,65)$ The disadvantage of using $\mathrm{ScvO}_{2}$ in prehospital setting is to ensure sterile environment. Instead, we could use less invasive measurement of skeletal muscle oxygen tension to provide rapid and noninvasive estimation of $\mathrm{SvO}_{2}$ in patients with severe left heart failure. (47)

\section{REFERENCES}

1.Dick FW. Anglo-American vs. Franco-German emergency medical services system. Prehosp Disaster Med 2003;18(1):29-35.

2.Grmec Š, Mally S. Emergency Medicine in Slovenia: Emergency Centre, Prehospital Emergency medicine and academic Emergency Medicine. Liječ Vjesn 2009;131(Supl 4):16-20.

3.Dickinson ET,Schneider RM,Verdile VP. The impact of prehospital physician on out-of-hospital nonasystolic cardiac arrest. Prehosp Emerg Care 1997; 1(3):132-5.

4.Benitez FL, Pepe PE. Role of the physcian in prehopsital management of trauma: North American Perspective. Curr Opin Crit Care 2002;8(6).551-8.

5. Moecke H,von Knobelsdorff $\mathrm{G}$. The anesthesiologist in prehospital and hospital emergency medicine. Curr Opin Anaesthesiol 2008;21(2):228 -32.

6.Timmermann A, Russo SG,Hollmann MW. Paramedic versus emergency physician emergency medical service: role of the anaesthesiologist and the Europena versus the Anglo-American concept. Curr Opin Anaesthesiol 2008;21(2):222-7.

7.Gazmuri RJ, Tandon M. Cardiopulmonry resuscitation:from flying blind to flying rigt. Crit Care Med 2008;36:357-9.

8.Ginsburg GS, Donahue MP, Newby LK. Prospects for personalized cardiovascular medicine:the impact of genomics. J Am Coll Cardiol 2005;46(9):1615-27

9.Synderman R, Yoediono Z. Perspective: Prospective health care and the role of academic medicine:lead,follow,or get out of the way. Acad Med 2008; 83(8):707-14

10.Auffray C,Chen Z, Hood L. Systems medicine:the future of medical genomics and healthcare. Genome Med 2009;1:2.

11. Meyers CM,Weingart SD.Critical care monitoring in emergency department. Emerg Med Practice 2007;9(7):2-27.

12.Grmec Š, Lah K. Clinical applications of capnometry/capnography and research in the Centre for emergency Medicine Maribor. Neurol Croat 2007:56(Suppl.4):59-68.

13.Grmec Š. Emergency endotracheal intubation:malposition and early detection. Int J Intensiv Care 2005;12(2):81-6.

14.Grmec Š. Comparison of three defferent methods to confirm tracheal tube placement in emergency intubation. Intensive Care Med 2002; 28(6):701-4.

15.Grmec Š. Capnography - reliable technique for identifying correct tube placement in cardiac arrest endotracheal intubations. Resuscitation 2008;77(3):416-7.

16.Grmec S, Klemen P. Does the end-tidal carbon dioxide (EtCO2) concentration have prognostic value during out-of-hospital cardiac arrest? Eur J Emerg Med 2001;8:263-9.

17.Grmec S, Kupnik D. Does the Mainz Emergency Evaluation Scoring (MEES) in combination with capnometry (MEESc) help in the prognosis of outcome from cardiopulmonary resuscitation in a prehospital setting? Resuscitation 2003;58:89-96.

18.Grmec S, Lah K, Tušek Bunc K. Difference in end-tidal CO2 between asphyxia cardiac arrest and ventricular fibrillation/pulseless ventricular tachycardia cardiac arrest in the prehospital setting. Crit Care 2003;7:R139-R44.

19.Grmec Š, Križmarić M, Mally Š, Koželj A, Špindler M, Lešnik B. Utstein style analysis of out-of-hospital cardiac arrest-Bystander CPR and end expired carbon dioxide. Resuscitation 2007;72(3):404-14. 
20.Kolar M, Križmarić M, Klemen P, Grmec Š. Partial pressure of end-tidal carbon dioxide successful predicts cardiopulmonary resuscitation in the field - a prospective observational study.Crit Care.2008;12(5): R115 Š1-13Ć.

21.Križmarić M, Velič M, Štiglic G, Grmec Š, Kokol P. Intelligent analysis in predicting outcome of out-of-hospital cardiac arrest. Comput Methods Programs Biomed 2009;95(Suppl.1):S22-S32.

22.Prosen G, Grmec Š, Kupnik D, Križmarić M, Završnik J, Gazmuri RJ. Focused echocardiography and capnography during resuscitation from pulseless electrical activity after out-of-hospital cardiac arrest. Crit Care 2009; 13(Suppl.1): S25-S6.

23.Prosen G, Križmarić M,Završnik J, Grmec Š. Does echocardiographically confirmed pseudo-PEA in out of hospital cardiac arrest patients with constant values of petCO2 during compression pauses indicate modified treatment? J Int Med Res 2010;38(in press).

24.Hernandez C, Shuler K, Hannan H, Sonyika C, Likourezos A, Marshall J. C.A.U.S.E.: Cardiac arrest ultra-sound exam—a better approach to managing patients in primary non-arrhythmogenic cardiac arrest. Resuscitation 2007;76:198-206.

25. Breitkreutz R, Walcher F, Seeger FH. Focused echocardiographic evaluation in resuscitation management: Concept of an advanced life support—conformed algorithm. Crit Care Med 2007;35:5

26.Perera P, Mailhot T, Riley D, Mandavia D. The RUSH exam: Rapid Ultrasound in SHock in the evaluation of the critically III. Emerg Med Clin North Am 2010;28:29-56.

27.Bazzocchi M, Quaia E, Zuiani C, Moroldo ML. Trans-cranial Doppler: state of the art. Eur J Radiol 1998;27:141-8.

28. Haas M, Allendorfer J, Walcher F, Neumann-Haefelin T, Blaivas M, Seeger FH, et al. Focused examination of cerebral blood flow in periresuscitation: a new advanced life support compliant concept—an extension of the focused echocardiography evaluation in life support examination. Crit Ultrasound J 2010;2:1-12.

29. Heidenreich P A. Transesophageal echocardiography (TEE) in the critical care patient. Cardiol Clin 2000;18(4):789-805.

30. Memtsoudis SG, Rosenberger P, Loffler M, Eltzschig HK, Mizuguchi A, Shernan SK, et al. The usefulness of transesophageal echocardiography during intraoperative cardiac arrest in noncardiac surgery. Anesth Analg 2006;102(6):1653-7.

31. Kozakova M, Palombo C, Pittella G, Distante A. Transesophageal echocardiography in myocardial ischemia: a review. Echocardiography 1995;12(5):479-94

32. Krivec B, Voga G, Zuran I, Skale R, Pareznik R, Podbregar M, et al. Diagnosis and treatment of shock due to massive pulmonary embolism: approach with transesophageal echocardiography and intrapulmonary trombolysis. Chest 1997;112(5):1310-6.

33. Saito Y, Donohue A, Attai S, Vahdat A, Brar R, Handapangoda I, et al. The syndrome of cardiac tamponade with "small« pericardial effusion. Echocardiography. 2008;25(3):321-7.

34. Kini V, Logani S, Ky B, Chirinos JA, Ferrari VA, St John Sutton MG, et al. Transthoracic and transesophageal echocardiography for the indication of suspescted infective endocarditis: vegetations, blood cultures and imaging. J Am Soc Echocardiography 2010;23(4):396-402.

35.Shiga T, Wajima Z, Apfel C C, Inoue T, Ohe Y. Diagnostic accuracy of transesophageal echocardiography, helical computed tomography, and magnetic resonance imaging for suspected thoracic aortic dissection: systematic review and meta-analysis. Arch Intern Med 2006;166(13):1350-6.

36.Vignon P. Hemodynamic assessment of critically ill patients using echocardiography Doppler. Curr Opin Crit Care 2005;11(3):227-34 .

37.Anonymous. INVOS $®$ System, 2007 (cited July 2010). Available: http://www.somanetics.com/invos-system

38. Leal-Noval SR, Cayuela A, Arellano-Orden V, Marin-Caballos A, Padilla V, Ferrandiz-Millon C, et al. Invasive and noninvasive assessment of cerebral oxygenation in patients with severe traumatic brain injury. Intensive Care Med 2010;36:1309 -17.

39.Murkin JM, Arango M. Near-infrared spectroscopy as an index of brain and tissue oxygenation. Br J Anaesth 2009,103(Suppl1):3-13.

40.Weil MH, Tang W. Microvascular flow during mechanical cardiopulmonary resuscitation. Resuscitation 2010 Jan;81(1):5. Epub 2009 Dec 9.

41.Puyana JC, Pinsky MR. Searching for non-invasive markers of tissue hypoxia. Crit Care. 2010;14(2):R42. Epub 2010 Mar 23.

42.Fries M, Weil MH, Chang YT, Castillo C, Tang W. Microcirculation during cardiac arrest and resuscitation. Crit Care Med 2006 Dec;34(12 Suppl):S454-7.

43.Anonymous. i-STAT® System, 2008 (cited July 2010). Available: www.abbottpointofcare.com

44.Dascombe BJ, Reaburn PR, Sirotic AC, Coutts AJ. The reliability of the i-STAT clinical portable analyser. J Sci Med Sport 2007;10:135-40.

45.Sediame S, Zerah-Lancner F, d'Ortho MP, Adnot S, Harf A. Accuracy of the i-STAT bedside blood gas analyser. Eur Respir J 1999;14:214-7.

46.Payen D, Luengo C, Heyer L, Resche-Rigon M, Kerever S, Damoisel C, Losser MR. Is thenar tissue hemoglobin oxygen saturation in septic shock related to macrohemodynamic variables and outcome? Crit Care 2009;13 Suppl 5:S6. Epub 2009 Nov 30.

47.Podbregar M, Mozina H. Skeletal muscle oxygen saturation does not estimate mixed venous oxygen saturation in patients with severe left heart failure and additional severe sepsis or septic shock. Crit Care 2007;11(1):116.

48.Mozina H, Podbregar M. Near-infrared spectroscopy during stagnant ischemia estimates central venous oxygen saturation and mixed venous oxygen saturation discrepancy in patients with severe left heart failure and additional sepsis/septic shock. Crit Care 2010;14(2):R42. Epub 2010 Mar 23.

49.Leone M, Blidi S, Antonini F, Meyssignac B, Bordon S, Garcin F, et al. Oxygen tissue saturation is lower in nonsurvivors than in survivors after early resuscitation of septic shock. Anesthesiology 2009 Aug;111(2):366-71.

50.Cohn SM, Nathens AB, Moore FA, Rhee P, Puyana JC, Moore EE, et al. Tissue oxygen saturation predicts the development of organ dysfunction during traumatic shock resuscitation. J Trauma 2007 Jan;62(1):44-54. 
51.Zhao D, Weil MH, Tang W, Klouche K, Wann SR. Pupil diameter and light reaction during cardiac arrest and resuscitation. Crit Care Med 2001;29(4):825-8.

52.Condemi A, Donatello G, Mauro M, Spazzolini A, Zocchi C. Importance of puppillary and photomotor reflexex in cardiac resuscitation. Minerva Anestesiol 1981;47(12):885-90.

53.Snyder BD, Gumnit RJ, Leppik IE, Hauser WA, Loewenson RB, Ramirez-Lassepas M. Neurologic prognosis after cardiopulmonary arrest: IV.Brainstem reflexes. Neurology 1981;31(9):1092-7.

54.Abe T, Tokuda Y, Ishimatsu S, Nagao K, Kikushima K, Sakamoto T, et al. Predictors for good cerebral performance among adult survivors of out-of-hospital cardiac arrest. Resuscitation 2009;80(4):431-6.

55.Marx G, Reinhart K. Venous oximetry. Curr Opin Crit Care 2006;12(3):263-8.

56. Andrews F J, Nolan J P. Critical care in the emergency department: monitoring the critically ill patient. Emerg Med Manual 2006;23(7):561-4.

57. Ahrens T. Hemodynamics in sepsis. AACN Adv Crit Care 2006;17(4):435-45.

58. Reinhart K, Kuhn H J, Hartog C, Bredle D L. Continous central venous and pulmonary artery oxygen saturation monitoring in the critically ill. Intensive Care Med 2004;30(8):1572-8.

59. Rivers E. Mixed and central venous oxygen saturation may be not numerically equal, but both are still clinically useful. Chest 2006;129(3):507-8.

60. Molnar Z, Umgleter A, Toth I, Livingstone D, Weyland A, Sakka SG, et al. Continous monitoring of ScvO(2) by a new fibre-optic technology compared with blood gas oximetry in critically ill patients: a multicenter study. Intensive Care Med 2007;33(10):1767-70.

61. Bauer P, Reinhart K, Bauer M. Significance of venous oximetry in the critically ill. Med Intensiva 2008;32(3):134-42.

62.Ruiz C, Hernandez G, Ince C. Diagnosis and treatment of the septic microcirculation. In: Vincent JL, editor. 2010 Yearbook of intensive care and emergency medicine, Berlin: Springer-Verlag; 2010. p. 16-26.

63.Lima A, van Bommel J, Jansen TC, Ince C, Bakker J. Low tissue oxygen saturation at the end of early goal-directed therapy is associated with worse outcome in critically ill patients. Crit Care 2009;13 Suppl 5:S13.

64.Di Filippo A, Gonnelli C, Perretta L, Zagli G, Spina R, Chiostri M, et al. Low central venous saturation predicts poor outcome in patients with brain injury after major trauma: a prospective observational study. Scand J Trauma Resusc Emerg 2009;17(1):23.

65. Secher NH, van Lieshout JJ. Normovolaemia defined by central blood volume and venous oxygen saturation. Cli Exp Pharmacol Physiol 2005;32(11):901-10. 